\title{
PHARMACEUTICAL PRODUCT QUALITY
}

\begin{tabular}{|c|c|}
\hline \multicolumn{2}{|c|}{ Practical information at a glance } \\
\hline $\begin{array}{l}\text { Proper storage of } \\
\text { contrast media }\end{array}$ & $\begin{array}{l}\text { - in a dark place (e.g. in a cupboard) } \\
\text { - at room temperatures }\left(15-25^{\circ} \mathrm{C}\right) \\
\text { - in a warming cabinet at } 37^{\circ} \mathrm{C} \text { for no longer than } \\
\quad 3 \text { months }\end{array}$ \\
\hline $\begin{array}{l}\text { Observation of } \\
\text { expiry dates }\end{array}$ & $\begin{array}{l}\text { - shelf-life of established contrast medium products } \\
\text { usually is up to } 5 \text { years } \\
\text { (as for other pharmaceutical products) } \\
\text { - expiry dates displayed on the packaging must } \\
\text { be adhered to }\end{array}$ \\
\hline $\begin{array}{l}\text { Examination of the } \mathrm{CM} \\
\text { solution before use }\end{array}$ & $\begin{array}{l}\text { - remove outer packing only shortly before use } \\
\text { - check clearness of solution } \\
\text { (no discoloration, no cloudiness, no precipitates) }\end{array}$ \\
\hline $\begin{array}{l}\text { Cystallization } \\
\text { found in solution }\end{array}$ & $\begin{array}{l}\text { - can occur at low temperatures (in winter), heat CM } \\
\text { solution briefly to } 80^{\circ} \mathrm{C} \text { before use; do not use if not } \\
\text { completely dissolved }\end{array}$ \\
\hline $\begin{array}{l}\text { CM solution with } \\
\text { high viscosity }\end{array}$ & $\begin{array}{l}\text { - heat solution to } 37^{\circ} \mathrm{C} \text {, this reduces viscosity and } \\
\text { allows solution to drawn up better }\end{array}$ \\
\hline $\begin{array}{l}\text { Risks of microbial } \\
\text { contamination }\end{array}$ & $\begin{array}{l}\text { - do not keep opened vials and ampoules longer than } \\
\text { one working day after first use; discard all remains at } \\
\text { the end of the day }\end{array}$ \\
\hline $\begin{array}{l}\text { Resterilization of } \\
\text { the CM solution }\end{array}$ & - do not resterilize opened containers \\
\hline $\begin{array}{l}\text { Transfer into } \\
\text { sterile containers }\end{array}$ & $\begin{array}{l}\text { - do not pour CM solution over the unsterile lip of the } \\
\text { original container, keep it covered, and do not return } \\
\text { it to the original vial }\end{array}$ \\
\hline
\end{tabular}




\section{Purity of the active ingredient, by- \\ products and degradation products}

Because of the high doses employed - which can exceed $100 \mathrm{~g}$ of substance per patient and examination - very high demands are made on CM in terms of chemical purity. The molecular structure of the CM substance is confirmed by NMR (nuclear magnetic resonance), , IR (infra red), MS (mass spectrometry) and UV (ultraviolet) spectra (fig. 13a-e).

In addition, contrast media are tested for foreign substances using thin-layer chromatography (fig. 13e) and high-pressure liquid chromatography (HPLC) to identify any by-products originating from synthesis $[18,19]$. The total iodine content is calculated by means of micro-iodine determination following wet combustion of a sample; the active ingredient content is determined by spectral photometric measurement or HPLC.

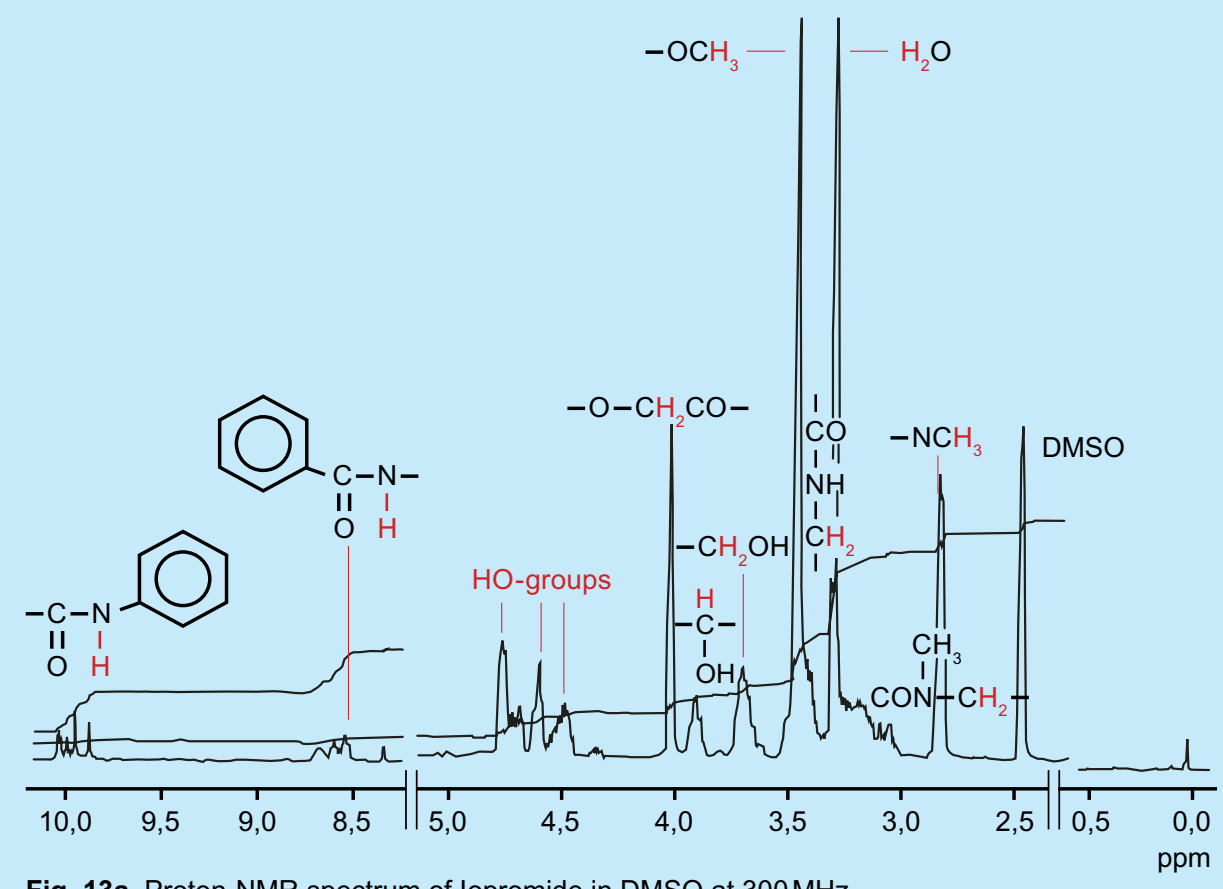

Fig. 13a. Proton-NMR spectrum of lopromide in DMSO at $300 \mathrm{MHz}$ 


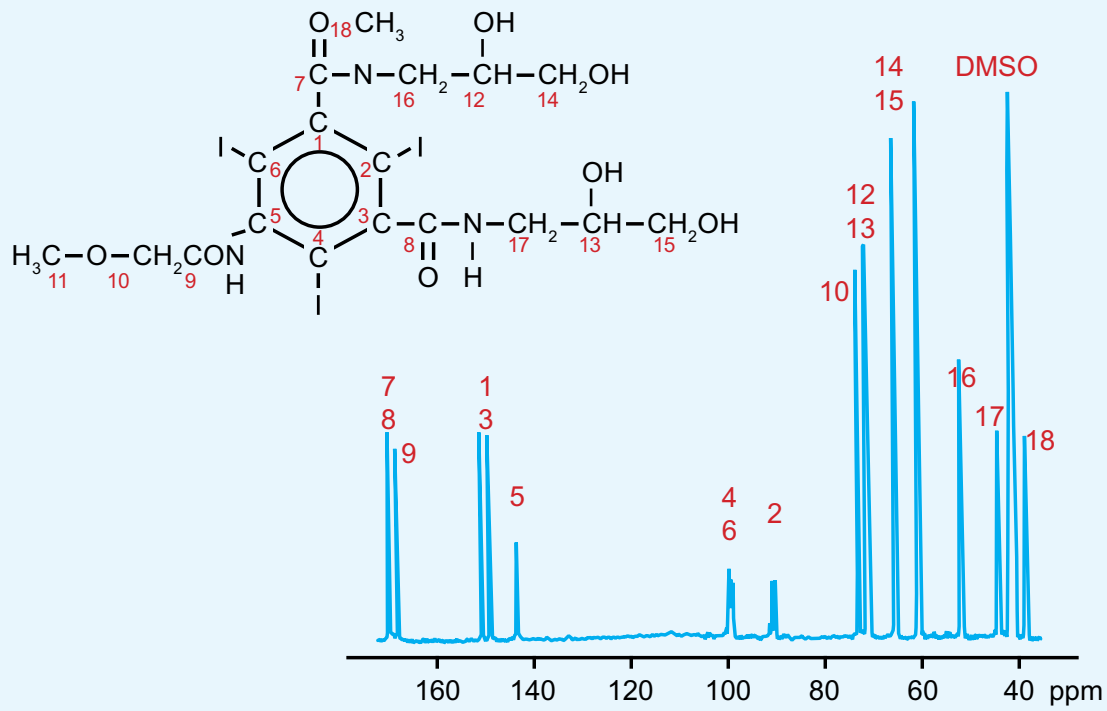

Fig. 13b. ${ }^{13} \mathrm{C}-\mathrm{NMR}$-spectrum of lopromide in DMSO at $75.5 \mathrm{MHz}$

The prescribed values for $\mathrm{CM}$ content are $98-102 \%$. In addition, tests for purity are performed using suitable customary pharmacopoeia methods: these include evaluation of color, clarity and $\mathrm{pH}$ of the test solution; water content, sulfate ash, and heavy metal contamination and tests for anorganic iodide and aromatic amine; TLC (thin-layer chromatography) for foreign substances. Nonionic CM are also tested for ionic contamination by measuring their conductivity.

Two particular reactions are of importance with regard to the storage of $\mathrm{CM}$ solutions: hydrolysis of amide bonds and cleavage of iodide [20].
Hydrolysis is suggested either by (additional) free carboxyl groups occurring at the aromate (with a strongly acidic reaction) and aliphatic amines or by the occurrence of aliphatic carbonic acids and aromatic amines.

Cleavage of iodine from the aromate leads to an increase of iodide in the solution; no elementary iodine is released. Degradation reactions of $\mathrm{CM}$ usually manifest as changes in $\mathrm{pH}$. 
Extinction Wavelength $\lambda$ in $\mu \mathrm{m}$

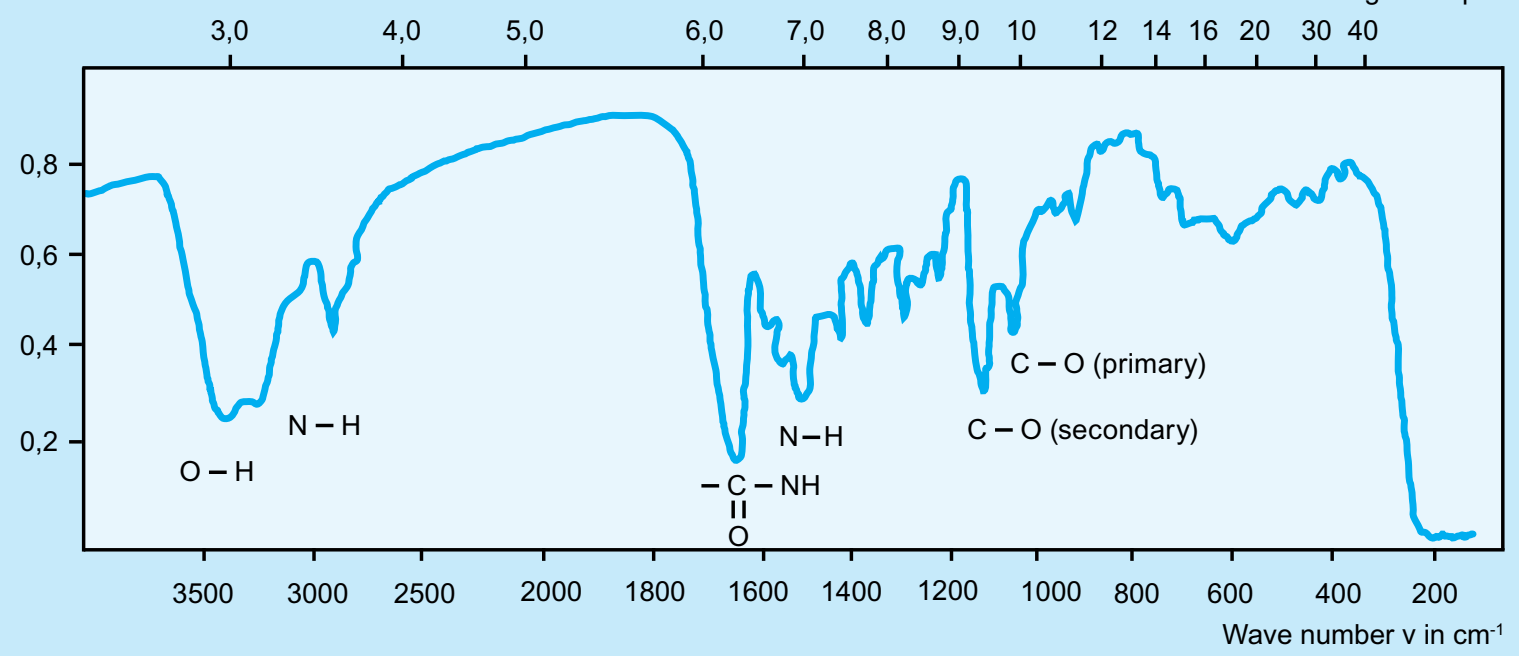

Fig. 13c. Infrared spectrum of lopromide in $\mathrm{KBr}$

\section{Formulations}

X-ray contrast media are usually offered as ready-to-inject aqueous solutions with the exception of Lipiodol and barium sulphate. Attention must be paid to the following properties with regard to use:

- type and amount of the CM substance,

- where applicable, type or mixture of salts,

- iodine concentration in the solution in $\mathrm{mg} / \mathrm{ml}$.

However, it has to be kept in mind that the concentration of the active ingredient in the $\mathrm{CM}$ solution alone rarely allows predicting opacification.

\section{Additives}

In addition to the $\mathrm{CM}$ substance and water, the finished preparations also contain pharmacologically relevant adjuvants. $\mathrm{CaNa}_{2}$ EDTA (calcium disodium ethylene-diamine tetraacetic acid) is pharmacologically virtually inactive in the concentrations used. It is employed as a stabilizer to prevent iodide release from the organic bond caused by heavy metal catalysis, e.g., by traces of $\mathrm{Cu}^{2+}$. Sodium EDTA used to be added for this purpose, butits calcium-binding property led to a reduction of cardiac contractility in cardioangiography. 


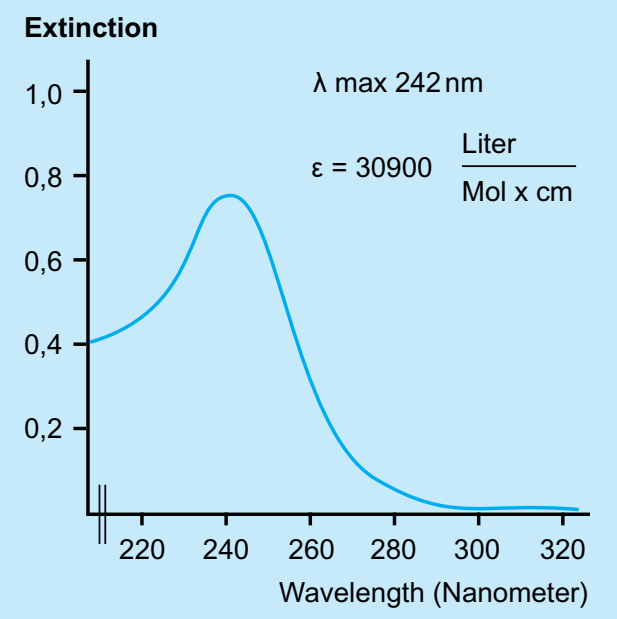

Fig. 13d. Ultraviolet spectrum of iopromide in water $(24 \mu \mathrm{g}$ iopromide $/ \mathrm{ml}$ slice thickness $=1 \mathrm{~cm})$

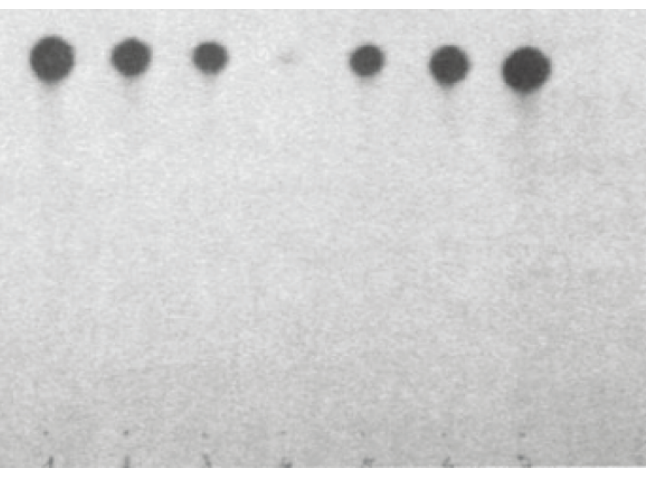

Fig. 13e. Thin-layer chromatogram of iopromide on a silica gel plate 60F-254 (Merck). Solvent: dioxane (85)-water (15)-ammonia (4). Amounts applied from left to right: $200 \mu \mathrm{g}, 100 \mu \mathrm{g}, 50 \mu \mathrm{g}, 1 \mu \mathrm{g}, 50 \mu \mathrm{g}$, $100 \mu \mathrm{g}, 200 \mu \mathrm{g}$. Photograph taken at $254 \mathrm{~nm}$
This effect is not observed with $\mathrm{CaNa}_{2}$ EDTA [21]. Formulations of the nonionic CM Ultravist and Omnipaque contain $0.1 \mathrm{mg} / \mathrm{ml} \mathrm{CaNa}{ }_{2}$ EDTA.

Buffers can be added to stabilize the $\mathrm{pH}$ of $\mathrm{CM}$ during storage. Tris and carbonate buffers, of which only low concentrations are required, are particularly suitable. The $\mathrm{pH}$ of $\mathrm{CM}$ solutions is approximately in the physiological range. The buffering effect is only slight.

After injection, the $\mathrm{pH}$ quickly adapts to that of blood. The formulations of Omnipaque and Ultravist contain 1.21 and $2.42 \mathrm{mg} / \mathrm{ml}$ Tris, respectively, with chloride as the counterion.

Preservatives (parabenes) may be present in $\mathrm{CM}$ for retrograde urography, while oral $\mathrm{CM}$ for examinations of the GI tract may contain flavoring agents and emulsifiers.

\section{Microbiological quality of the finished product \\ Production under controlled environmental conditions}

The manufacture of solutions for injection and infusion requires special hygienic measures determined by the production facilities, the technical equipment and the workers' competence.

Manufacturers must meet not only international and national legal regulations and guidelines for pharmaceutical products, but also the much stricter requirements for the production of X-ray contrast media (fig. 14 a-f). 
Further reduction of microbiological contamination is achieved by dividing the entire working area into cleanliness classes:

Designing production rooms as differently controlled areas aims at preventing possible particular and microbiological impurities and cross-contaminations while producing contrast media:

CRCA: Clean room Class A - rooms for hazardous work processes (aseptic production and filling, irrelevant for production of final sterilized products)

CRCB: Clean room Class B - surrounding area of CRCA in case of aseptic production and filling

CRCC: Clean room Class C - Filling of solutions without extraordinary risk of particulate matter and microbiological contamination

CRCD: Clean room Class D - production of bulk-solutions without extraordinary risk for microbiological and particulate matter contamination

An air-conditioning system regulated centrally via microprocessor provides for the necessary environmental conditions at the individual workplaces. In aseptic working zones, laminar-flow units - special filter units - in addition to the conventional sterile air supply protect the product from the risk of contamination by man and environment. 


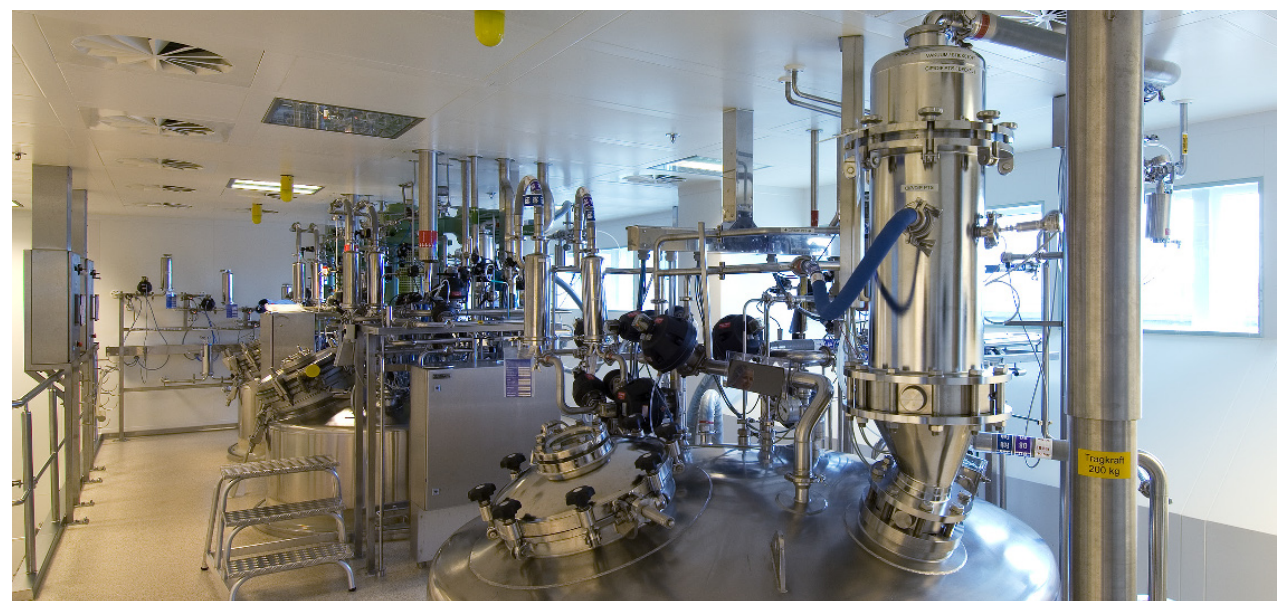

Fig. 14a. Production of solutions and temporary storage

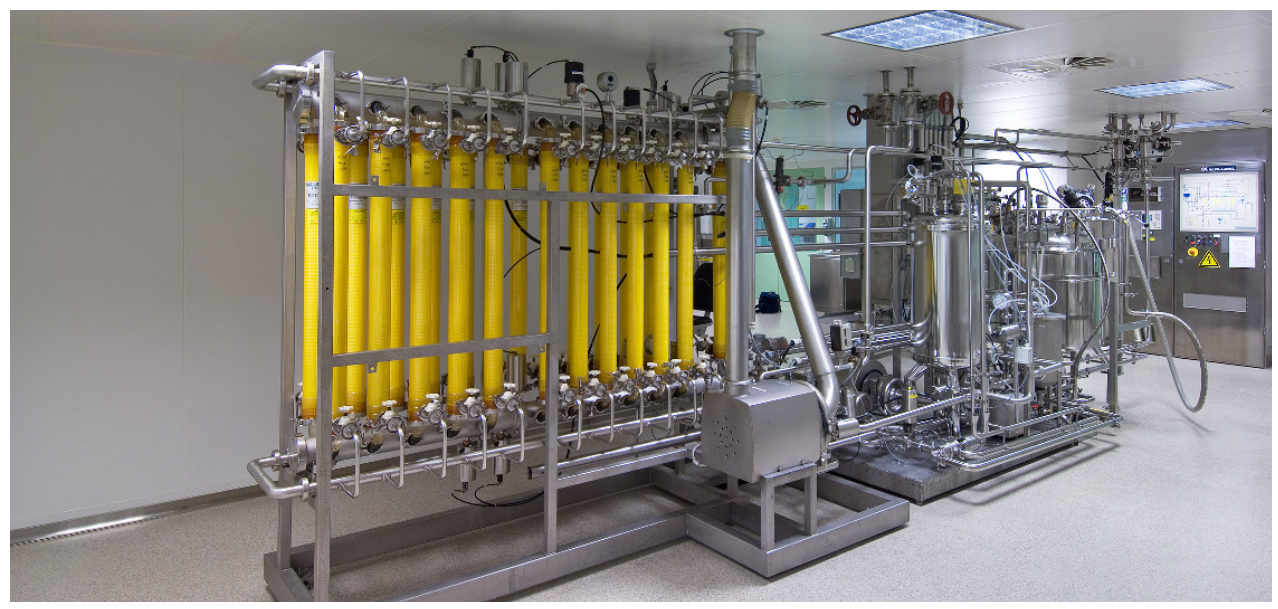

Fig. 14b. Ultrafiltration facility

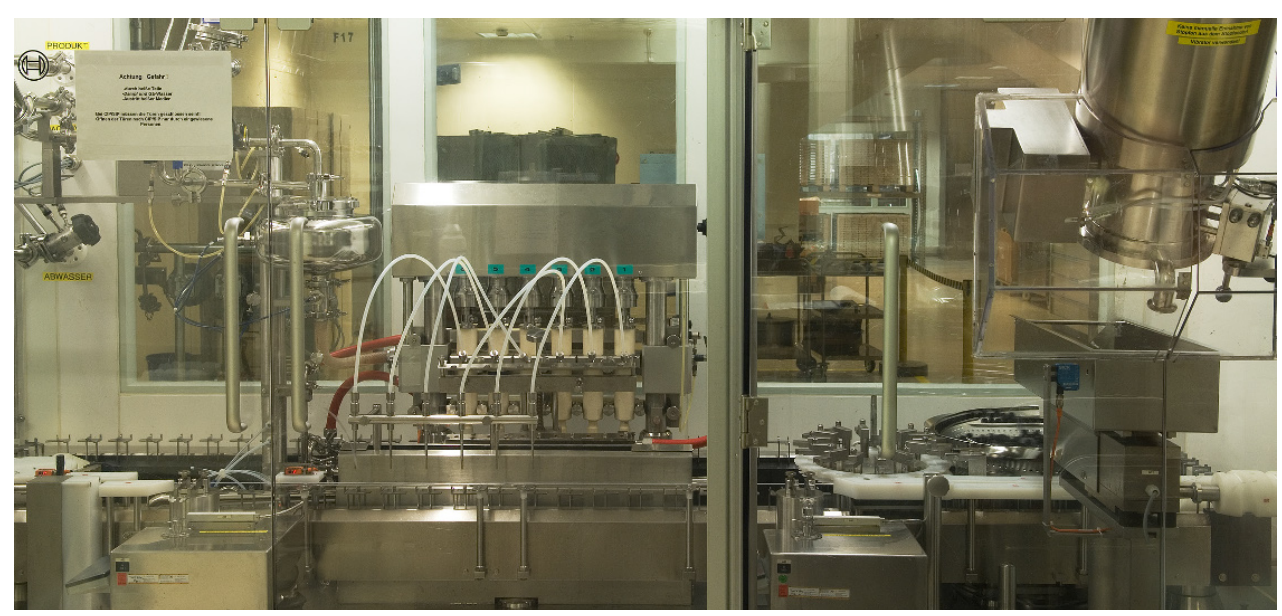

Fig. 14c. Infusion bottle line - filling machine under laminar flow 


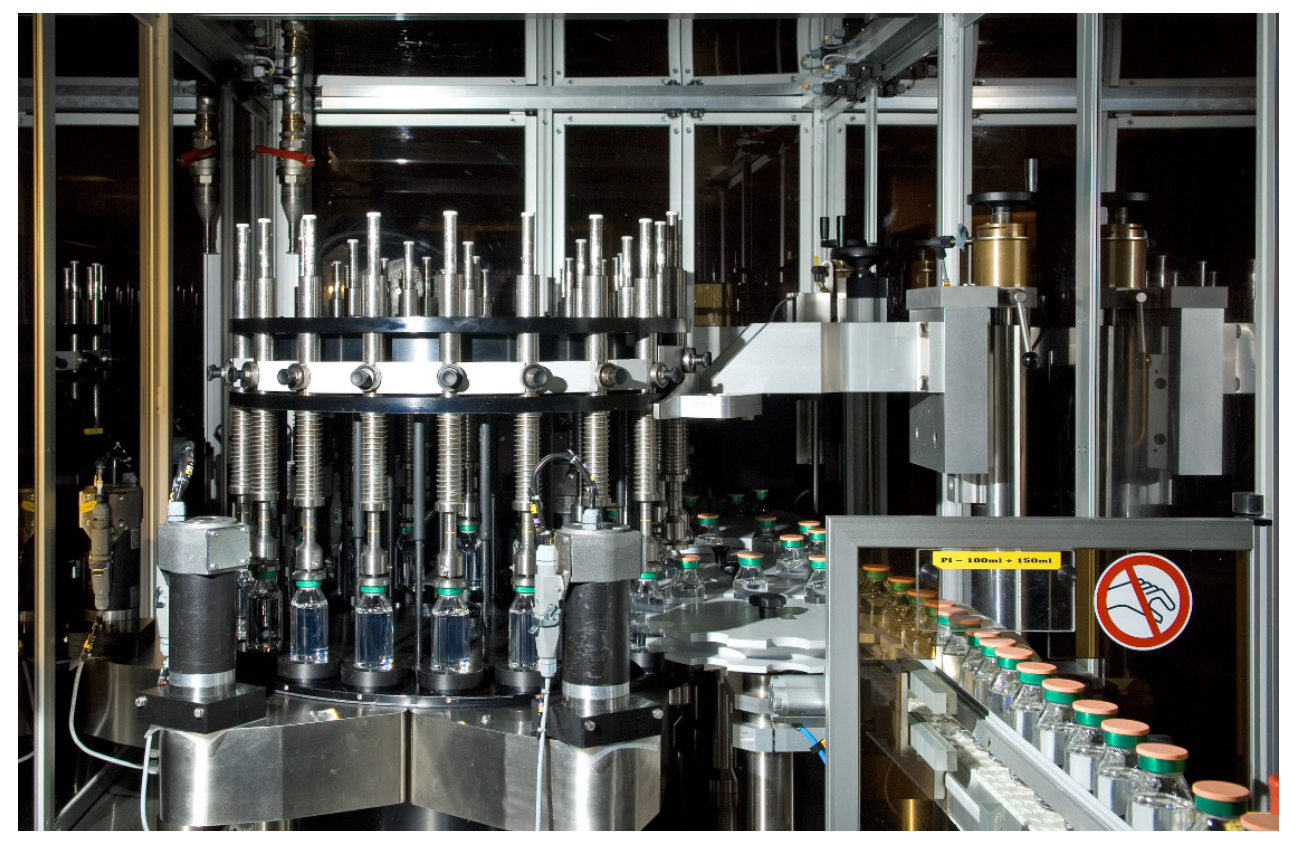

Fig. 14d. Electronic control of infusion bottles

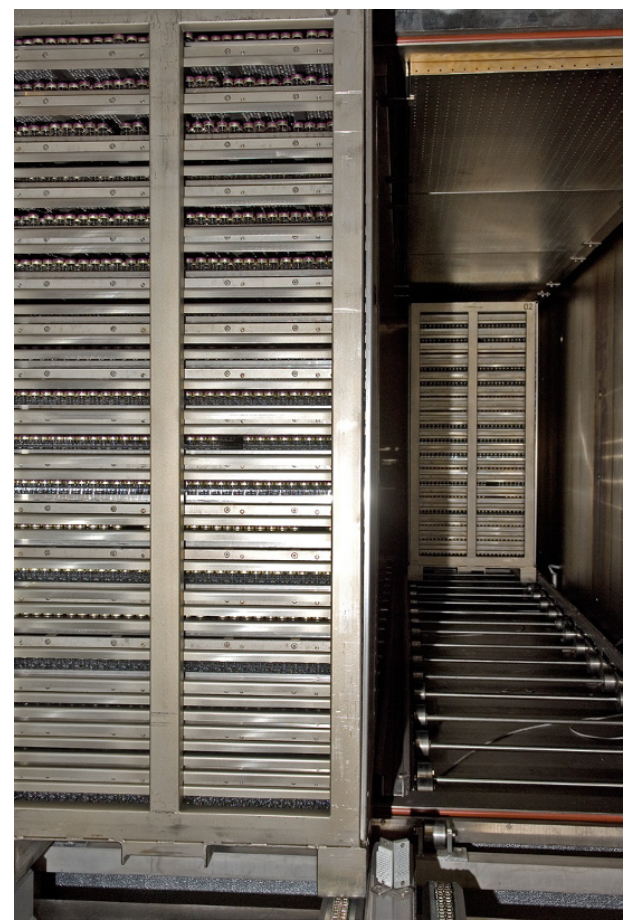

Fig. 14e. Sterilisation

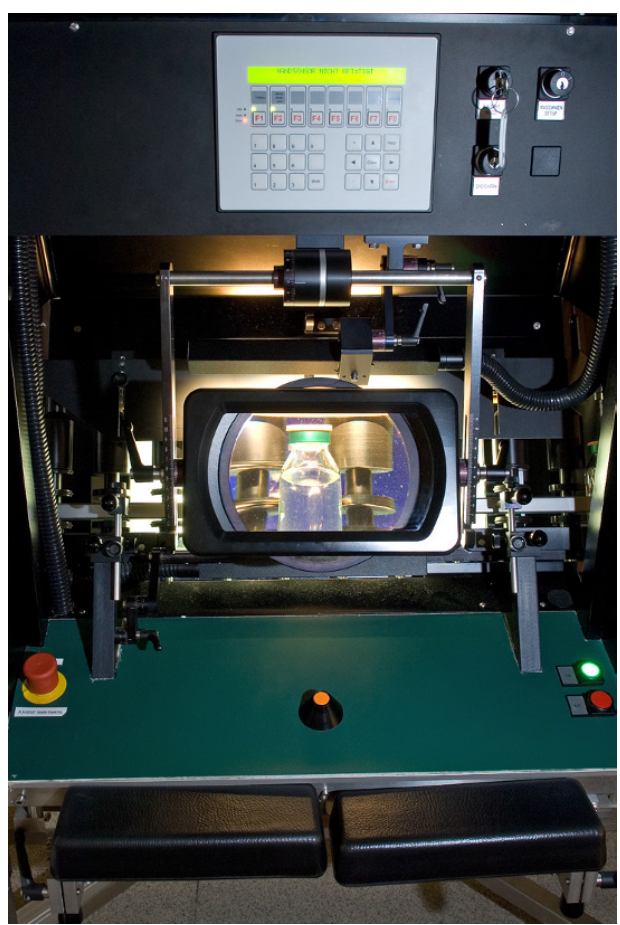

Fig. 14f. Visual control of infusion bottles 
Mechanical production lines have been automated as much as possible to reduce the risks which can arise through direct contact between staff and products during these procedural steps. Examples are computer-controlled cleaning processes for cleaning agitators, pressure tanks and other equipment.

Strict observance of all pharmaceutical rules and the proper use of technical equipment require qualified staff consisting of pharmacists, engineers, technicians and skilled workers, who undergo regular training and thus apply the latest scientific and technical insights.

\section{Production process}

Table 7 provides a simplified schematic production flow of CM manufacture.

Of interest here is the number of steps in the production. Each production step is followed by a process control step to ensure that a given production step has been carried out as specified before the next step is initiated. Thus, the sum of the results of the individual process control steps describes the quality of the finished product and says more about it than the finished article or final control, the result of which can only be based on selected samples.

Let's just follow the production flow described in table 7:

The ingredients and packing material are checked as they come in and, after release by quality control and cleaning of the outer surfaces, are packed on pallets for intermediate storage. 


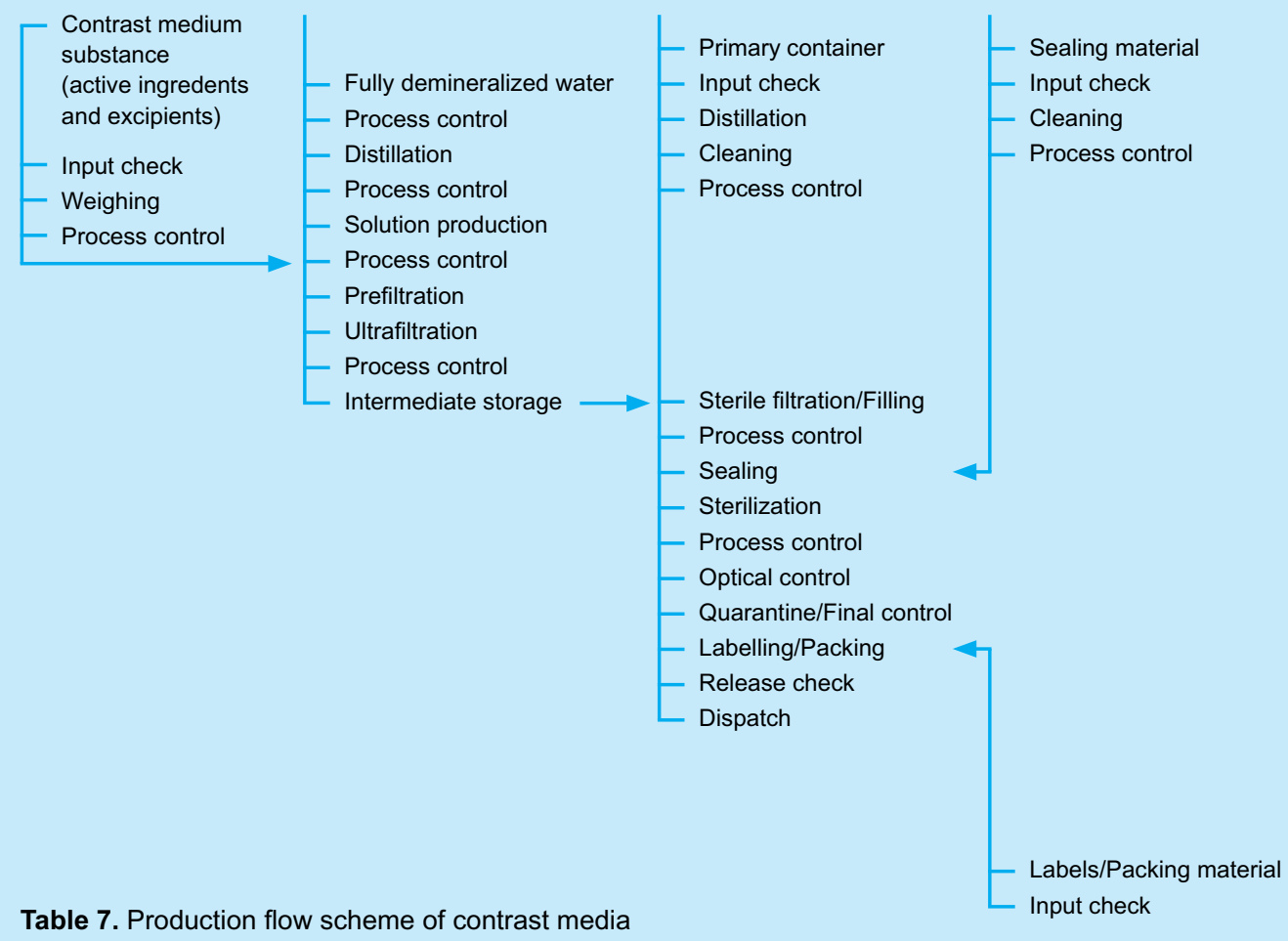

The amounts of active substance and adjuvants specified in the prescription for a batch of the respective preparation are weighed in a weighing center and the data documented via an automatic control system. After an identity check, the substances are brought in special containers to the make-up rooms and dissolved in a stirring apparatus.

The various chemical and physical data of the testing standard are checked before the solution undergoes sterile filtration. During filtration, all micro-organisms and contaminating particles are sieved out of the solution. Particles down to a size of a 5,000th of a millimeter can be filtered out. After this step, the solutions are ready for filling and are led into the filling plant via a special system of pipes. 
Vials are cleaned, for instance by ultrasound, sterilized, filled and sealed in a special cleaning, filling and sealing machine. The process is accompanied by a check on the amount filled.

Although the fact that the production rooms are aseptic means that filling can take place without contamination from the environment, the filling machines are further protected by a laminar-flow arrangement. The filled and sealed containers undergo final sterilization in steam autoclaves.

Finally, all filled products are examined for possible particulate contamination.

Optical inspection can be done fully automatically or visually. Visual inspection is performed by specifically educated staff. During the inspection, the objects rotate in front of an illuminated background and are observed through a magnifier. Different options exist for fully automatic inspection:

- Measurement of attenuation of light intensity caused by particles using an Evaporative Light Scattering Detector (ELSD)

- Evaluation of photographs of the rotating probes

- A combination of the above

The final medical product batch is then transferred to a quarantine storage house and approved for packaging after a final control by the pharmaceutical quality management. 
Sterile filtration, ultrafiltration and sterilization

All starting materials, such as active ingredients, pure water, containers and stoppers, are constantly checked for microbial contaminations.

Sterile filtration of the solutions and sterilization of the filled containers ensure the necessary sterility. In addition, what is known as molecular or ultrafiltration can be performed. This process is used in the production of contrast media like Ultravist and is able to retain molecules above a molecular weight of $10,000 \mathrm{D}$. It ensures that not only micro-organisms but also their high-molecular-weight metabolic products including pyrogens are withdrawn, resulting in a distinct reduction of the particle content in the lower micrometer range. In addition, the CM solution passes through a sterile filter while it is being filled into the vials.

Finally, the finished, firmly sealed individual containers are autoclaved for $20 \mathrm{~min}$ at $121^{\circ} \mathrm{C}$. The containers are heated for the shortest possible time by superheated steam and cooled again quickly by being sprayed with water. This is important because the chemical stability of the CM is limited at such high temperatures. 


\section{Sterility test}

Sterility testing is done to check whether micro-organisms capable of multiplication can be demonstrated in the final product. Sterility is tested using the Millipore-Steritest system for two culture media. The contents of 20 containers from each batch manufactured in the production line undergo membrane filtration via the Steritest system: the membrane, which has an average pore diameter of $\leq 0.45 \mu \mathrm{m}$, retains any micro-organisms present.

The contents of each container are distributed evenly to two filter units and filtered. One filter is then coated with the culture medium casein-peptone/soyapeptone bouillon, the other filter with thioglycolate medium. The entire filter units are incubated for 10 days to allow micro-organisms to grow. At the end of the incubated period, the filter units are checked for macroscopically visible growth (turbidity). The sterility requirements are fulfilled when the culture media remain clear after brief shaking.

\section{Test for pyrogens}

Fever reactions can occur in humans and animals after parenteral administration of injection and infusion solutions. The reactions are frequently caused by microbial metabolic and degradation products or endotoxins (constituents of the cell walls of gram-negative bacteria). These fever-producing substances with a chemically heterogeneous structure are known as pyrogens. 
The commonest internationally used test to detect and quantitate endotoxic contamination by gram-negative bacteria in drugs is the LAL (limulus amebocyte lysate) test, which is described in detail in the relevant pharmacopoeias. It is named after the horseshoe crab Limulus polyphemus, because the amebocyte lysate of its blood is used in the test.

Different techniques can be used to perform the LAL test:

- Gel-clot method (based on gel formation)

- Turbidimetric method (based on turbidity after cleavage of an endogeneous substrate)

- Chromogenic method (based on colour formation after cleavage of peptide chromogen complex)

The LAL test, an in vitro pyrogen test, is a limited alternative to the rabbit test, which is an in vivo pyrogen test to detect pyrogenic contamination in drugs.

Rabbits react quickly to the slightest pyrogenic impurity in an intravenously injected solution with an increase of body temperature. The method of testing is described in detail in the relevant pharmacopoeias. Although the rabbit test is not mandatory in Europe and the US anymore, it is still used in some countries. The LAL test is limited by the fact that it is only able to specifically demonstrate bacterial endotoxins. The latter are the most common impurities with the highest pyrogenic activity. 


\section{Preservation of product quality in hospitals and practices}

After filling and sterilization, the CM undergo a final and thorough quality check. After manufacture, it may be a while before the products are actually used - a period in which the products are transported and stored under varying conditions. Finally, the vials are opened or the stoppers are pierced, and the CM solution is drawn up directly into syringes or automatic injectors. It may be infused through an infusion kit or transferred to another container. The content of a vial is to be used up immediately after opening.

Transport, storage and handling during use may impair the quality of a $\mathrm{CM}$ solution. A number of influences to which the products may be exposed after the final control by the manufacturer have been simulated in the laboratory and examined for their effect on the quality of the solutions. The user should always recheck the clarity of the solution immediately before use (see page 38 ).

\section{Stability in long-term storage and at different temperatures}

One of the most important checks on CM solutions concerns their long-term stability. To ensure high quality up to actual use, every effort is made to develop the CM formulation and to choose the container materials in such a way that storage under normal conditions is possible for up to 5 years. Since insufficient experience is usually available at the time a new product is introduced to be able to prove such sustained stability; an expiry date on the order of 2 or 3 years is usually stated as a precaution. 
The stability of CM is satisfactory at room temperature $\left(15-25^{\circ} \mathrm{C}\right)$; there is no need to store the products in a cool place unless this is expressly mentioned on the label. Ionic CM (Gastrografin, etc.) can crystallize at temperatures close to freezing point, e.g., during transport in winter.

The crystals are usually easily recognizable and can be dissolved again in the unopened vial by brief heating to a maximum of $80^{\circ} \mathrm{C}$. Contrast media generally tolerate such brief heating without any problems, since they are heated to $121^{\circ} \mathrm{C}$ for $20 \mathrm{~min}$ after manufacture for final sterilization. The same naturally applies to warming the solution to body temperature before use to improve tolerance. Renewed sterilization of solutions from opened containers is not permitted.

Although prolonged storage (for months or years) at higher temperatures (e.g., $30^{\circ} \mathrm{C}$ ) does not result in surpassing the limits of the product's quality specifications, it should be avoided because higher temperatures accelerate degradation reactions.

Appearance alone does not always allow the user to recognize $\mathrm{CM}$ which no longer meet the quality specifications. Typical analytical changes are a decreased $\mathrm{pH}$ and an increase of iodide and degradation products. Discoloration, turbidity and sedimentation can be recognized with the naked eye and indicate imperfect quality. 


\begin{tabular}{ll}
$\mathrm{pH}$ value & $6.5-8.0$ \\
\hline Free amine & $\leq 0.1 \%$ \\
\hline lodide & $\leq 75 \mu \mathrm{g} / \mathrm{ml}$ solution \\
\hline Color & $\begin{array}{l}\leq \text { color of comparison } \\
\text { solution B5 or BG5 or G5 }\end{array}$ \\
\hline $\begin{array}{l}\text { Content of active } \\
\text { ingredient }\end{array}$ & $\leq 95-105 \%$ \\
\hline
\end{tabular}

Table 8. Quality features and their threshold values with Ultravist-240 as the example
When stored correctly, i.e., protected from light and X-rays, and when observing the limits for storage temperature and duration, the critical values listed in table 8 will not be exceeded. Ultravist-240, Ultravist-300, and Ultravist-370 are still stable even after storage for several years at temperatures of both $20^{\circ} \mathrm{C}$ and $30^{\circ} \mathrm{C}$ (table 9).
Sensitivity to irradiation and light: white glass, brown glass, and UV-protective foil

X-ray contrast media are sensitive to light and, to some extent, also to irradiation. They should be stored in the dark and for only a limited time close to X-ray units.

Although brown glass or UV-protective foil provides some protection against light, it has the major disadvantage that any particles which may occur (fragments of the stopper, crystals) are less easy to recognize. It is for this important reason that containers made of colorless glass are preferred.

\begin{tabular}{|c|c|c|c|c|c|c|c|}
\hline & \multirow[t]{2}{*}{$\begin{array}{l}\text { Storage } \\
\text { period }\end{array}$} & \multicolumn{2}{|c|}{$\begin{array}{l}\text { lodide } \\
\text { ( } \mu \mathrm{g} / \mathrm{ml})\end{array}$} & \multicolumn{2}{|c|}{$\begin{array}{c}\mathrm{pH} \\
\text { value }\end{array}$} & \multicolumn{2}{|c|}{$\begin{array}{c}\text { Substance } \\
\text { content as } \%\end{array}$} \\
\hline & & $20^{\circ} \mathrm{C}$ & $30^{\circ} \mathrm{C}$ & $20^{\circ} \mathrm{C}$ & $30^{\circ} \mathrm{C}$ & $20^{\circ} \mathrm{C}$ & $30^{\circ} \mathrm{C}$ \\
\hline Ultravist-240 & 0 & 1 & & 7.62 & & 100 & \\
\hline $50 \mathrm{ml}$ & 24 months & 6 & 11 & 7.51 & 7.50 & 99 & 99 \\
\hline Ultravist-300 & 0 & 3 & & 7.52 & & 100 & \\
\hline $50 \mathrm{ml}$ & 24 months & 6 & 14 & 7.34 & 7.23 & 99 & 100 \\
\hline Ultravist-370 & 0 & 3 & & 7.30 & & 100 & \\
\hline $50 \mathrm{ml}$ & 24 months & 13 & 35 & 7.29 & 7.09 & 99 & 99 \\
\hline
\end{tabular}

Table 9. Stability data of different formulations/ strengths of a nonionic CM 
Because usually the glass is colorless, however, it is especially important that the outer packing (carton etc.) not be removed until shortly before use or that the $\mathrm{CM}$ be stored in a dark place, e.g., in a cupboard. During normal manipulation and use, exposure to light of normal room brightness (approx. 600 lux, cf. fig. 15) is not critical, but exposure to sunlight must be avoided.

The sensitivity to X-ray irradiation is quite low. Irradiation of up to $10 \mathrm{rd}$ produced no relevant effect on either Urografin or Ultravist (table 10).

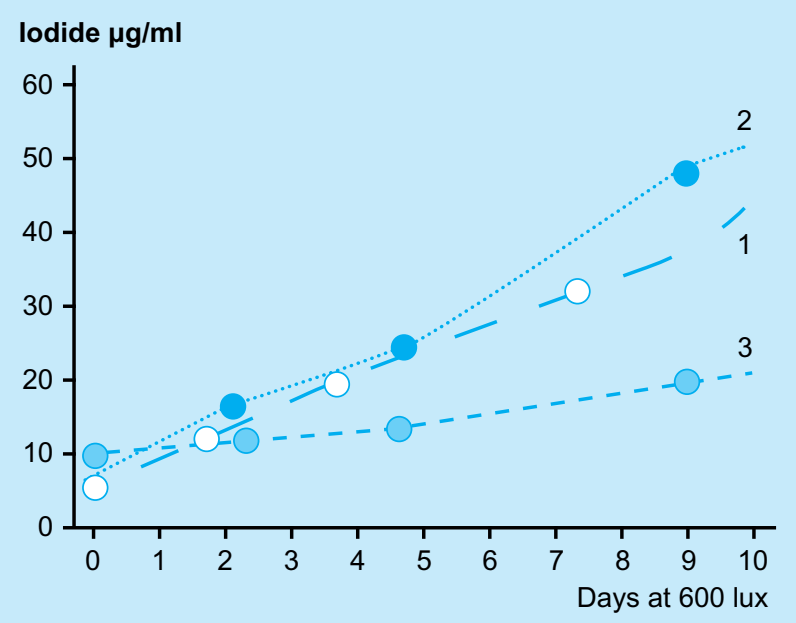

Fig. 15. Release of lodide from 3 different $\mathrm{CM}$ stored in a $50-\mathrm{ml}$ clear glass vial and illuminated

\begin{tabular}{|c|c|c|c|c|}
\hline & $\begin{array}{l}\text { Description } \\
\text { Color }\end{array}$ & $\begin{array}{c}\mathrm{pH} \\
\text { value }\end{array}$ & $\begin{array}{l}\text { lodide } \\
(\mu \mathrm{g} / \mathrm{ml})\end{array}$ & $\begin{array}{l}\text { Free amine } \\
\qquad(\%)\end{array}$ \\
\hline $\begin{array}{l}\text { Urografin } 30 \% \\
\text { Nonirradiated }\end{array}$ & $\begin{array}{l}\text { clear, colorless solution; } \\
<\mathrm{G} 6\end{array}$ & 6.63 & 3.7 & 0.006 \\
\hline $\begin{array}{l}\text { Urografin } 30 \% \\
1 \text { rd irradiated }\end{array}$ & Unchanged & 6.62 & 3.6 & 0.004 \\
\hline $\begin{array}{l}\text { Urografin } 30 \% \\
10 \text { rd irradiated }\end{array}$ & Unchanged & 6.62 & 3.6 & 0.006 \\
\hline $\begin{array}{l}\text { Ultravist-300 } \\
\text { Nonirradiated }\end{array}$ & $\begin{array}{l}\text { clear, colorless solution; } \\
\text { G6 }\end{array}$ & 7.60 & 2.5 & 0.017 \\
\hline $\begin{array}{l}\text { Ultravist-300 } \\
1 \text { rd irradiated }\end{array}$ & Unchanged & 7.60 & 3.2 & 0.017 \\
\hline $\begin{array}{l}\text { Ultravist-300 } \\
10 \text { rd irradiated }\end{array}$ & Unchanged & 7.60 & 3.3 & 0.018 \\
\hline
\end{tabular}

Table 10. Effects of X-ray irradiation on CM solution 


\section{Tests for contamination with particles}

Particles in the X-ray CM solution must be avoided at all costs. They represent one of the most serious problems in the manufacture and handling because $\mathrm{X}$-ray $\mathrm{CM}$ - unlike most infusion solutions - are injected not only intravenously but sometimes intra-arterially into the vessels of highly sensitive organs [22]. After their production, CM are checked very carefully for their content of the most minute particles. Particles subsequently occurring in closed containers may be CM crystals, which appear in individual solutions when kept at temperatures close to or below the freezing point. Unopened vials containing noncrystalline flocculation and unopened nonionic CM vials containing crystals or sediments are to be returned to the manufacturer immediately. Crystals - when caused by storage at low temperature - can be dissolved again as described on page 38 .

Contamination with particles can occur upon removal of the CM from the original container [23]. One possible cause is fragmentation of the stopper material. The punching-out of rubber particles and the formation of rubber shavings cannot be fully avoided when a rubber stopper is pierced by a cannula. This also applies, of course, to the sticker of infusion kits, although the kits offered by some manufacturers are fitted with appropriate fluid filters.

For testing purposes, stoppers were fitted to normal vials and pierced with cannulas. After a total of 20 stoppers were each pierced 5 times, i.e., after 100 piercings, the fragments are washed off, isolated on membrane filters and then counted. 
Comparative studies show that fragmentation is essentially dependent on the quality of cannula sharpening and cannula caliber.

Other factors with a less marked effect on fragmentation include stopper geometry, especially the thickness of the membrane that is pierced, and the stopper elastomer, its content of filler and hardness.

Handling also has a considerable influence. For example, care must be taken to never insert the cannula in exactly the same place twice when multiple doses are removed. Since most CM are offered as so-called single-dose preparations, however, this risk is avoided.

Even the shape in which the cannula is ground is important. Only cannulas ground to an acute or moderately acute angle should be used for piercing stoppers. Cannulas ground at an obtuse angle, e.g., those used as indwelling venous cannulas, increase the rate of fragmentation considerably. It goes without saying that the ground surface must be perfect. Cannulas which have become blunted, e.g., because they have been used several times and have hit the bottom of the vial, should be discarded.

The fragmentation rate obviously increases with the caliber of the cannula. Fragmentation of the stoppers increases decisively between $16 G$ and $18 G$ cannulas. 
There is a temptation to use a larger cannula to shorten the time taken to draw up the solution, particularly when, for example, $50 \mathrm{ml}$ of a relatively viscous CM solution is required. Instead, it is possible to reduce viscosity by about a half by warming the solution to $37^{\circ} \mathrm{C}$. Moreover, so-called combi stoppers need not be pierced and, instead, can be removed after tearing off the flanged cap. Of course, the solution can then only be drawn up with a syringe or with the syringe of a high-pressure injector. In the interest of sterility, the solution should not be poured out over the lip of the vial.

\section{Growth-promoting effect of iopromide} (Ultravist) on micro-organisms

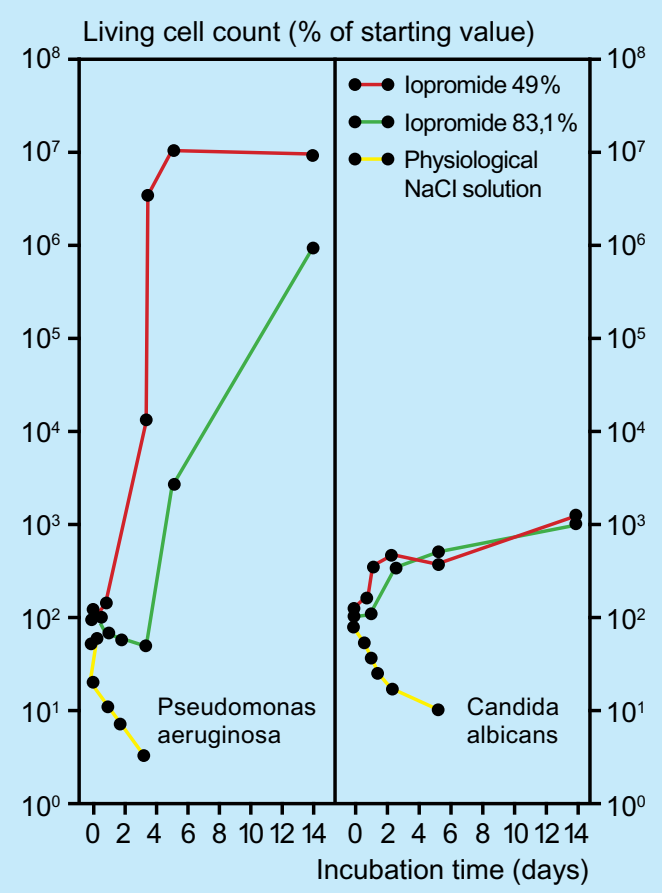

Fig. 16. Development of Candida albicans and Pseudomonas aeruginosa in aqueous solutions of a nonionic CM (Ultravist) at room temperature over a period of 14 days (incubation time)
Finally, there is also a possibility of particle contamination from syringes and catheters, and this is likewise very difficult to detect.

\section{Risks of microbial contamination}

Tri-iodinated CM were originally developed from antibacterial substances. The ionic CM still on the market have distinct antimicrobial activity, at least in the customary high concentrations of $300 \mathrm{mg} \mathrm{l} / \mathrm{ml}$ or more. This effect is attributable to two factors:

- the high osmolality and

- a residue of chemotoxicity.

In contrast, nonionic CM are a good culture medium for fungi and bacteria because of their chemical composition and tolerance [24].

The behavior of micro-organisms in a nonionic $\mathrm{CM}$ solution was studied in various Ultravist solutions (fig. 16). Six specimens of different groups of micro-organism were used as representatives of a broad spectrum of pathogens. 
The risk of microbial multiplication and spoiling of the product were simulated by artificial contamination in a model experiment:

Three of the 6 types of micro-organisms grew in Ultravist solutions:

- Pseudomonas aeruginosa (gram-negative bacterium, rod-shaped bacillus)

- Candida albicans (fungus, yeast)

- Aspergillus niger (fungus, mold).

The growth of Staphylococcus aureus (grampositive bacterium, coccus) was inhibited. The Ultravist solution had no effects on gram-positive, sporiferous bacteria: Bacillus subtilis (aerobic) and Clostridium sporogenes (anaerobic). Neither an increase nor a decrease of the germ count was found for these organisms.

The risk of microbial contamination of the $\mathrm{CM}$ in the production zone can be kept low if, during the manufacture, filling and sterilization, the time between making up the solution and subsequent antimicrobial treatment is kept as short as possible.

The following advice applies to the use of nonionic $\mathrm{CM}$ in particular:

- Careful avoidance of contamination of solutions and materials which come into contact with the solutions.

- Opened vials and ampoules to be used up in the course of one examination session if possible; keep for no longer than one working day after opening or removal of the first dose.

- All remains to be discarded at the end of a day to prevent their subsequent use. 


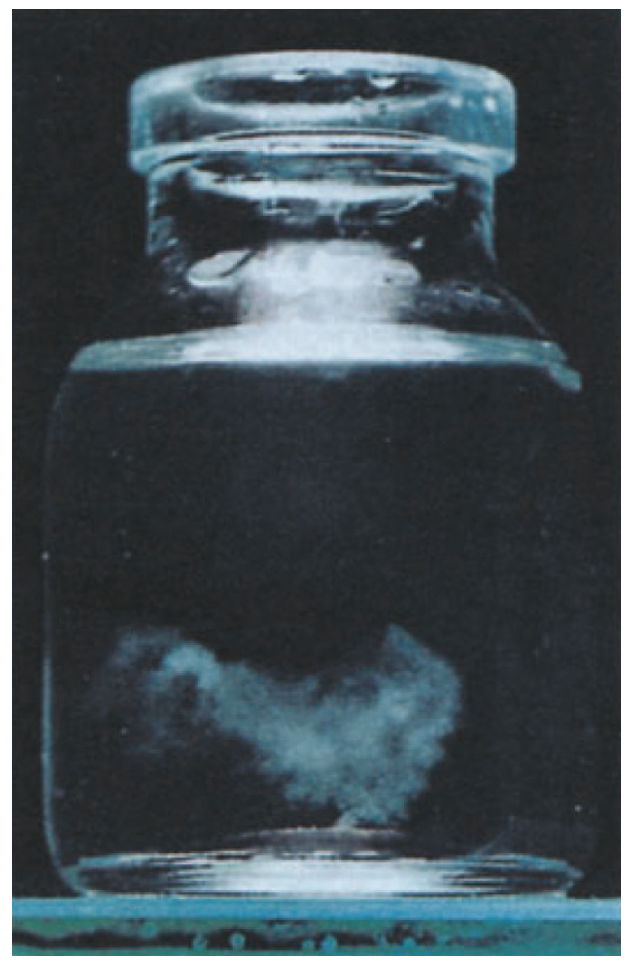

Fig. 17. Example of a microbially contaminated contrast medium solution. About 10 yeast cells were injected through the rubber stopper into the previously sterile contrast medium vial and then kept for about 3 weeks at room temperature. The development and maintenance of a fungal mycelium are promoted by the viscosity of the solution
Microbial contamination of $\mathrm{CM}$ solutions can, of course, only be recognized macroscopically at a very late stage. Fungal infection is characterized by a cloud of suspended particles resembling a cotton swab (fig. 17).

\section{Transferring the contrast medium to sterile containers, disposable syringes, automatic injectors}

Apart from the primary container, $\mathrm{CM}$ almost invariably come into contact with other containers, with syringes, tubes, catheters, injection needles, etc.

\section{Transferring to sterile containers}

Some X-ray examinations must be performed under absolutely aseptic conditions. In these cases, the $\mathrm{CM}$ is transferred to, for example, sterile containers, since the unsterile outer surface of the original container would be a possible source of contamination. Measures to be followed here are:

- The CM solution should not be poured over the unsterile lip of the original container, but should be removed with a large-caliber cannula after complete removal of the stopper.

- The solution should be covered to prevent drying-out with crystal formation.

- Stability in an open container is, of course, limited to a short time; under no circumstances should solutions be returned to the original vial. 


\section{Drawing-up into disposable syringes or automatic injectors}

When CM solutions are being drawn up from the original container into disposable syringes or filled into the syringes of high-pressure injectors, there exists - as with all opened vials - the risk of microbial contamination and subsequent multiplication as well as the possibility that ingredients of the plastic material or plunger will diffuse into the CM solution [25]. In all cases, the CM should not be drawn up into the syringes until immediately before use.

Table 11 shows a particularly unfavorable example. Constituents able to diffuse have been identified as 2-mercaptobenzothiazole and 2-hydroxyethylmer cabo benzothiazole. They reach concentrations of up to several $\mu \mathrm{g} / \mathrm{ml}$.

\begin{tabular}{ccc} 
Hours & $\mathbf{E}_{280 \mathrm{~nm}}$ & $\mathbf{p H}$ \\
\hline 0 & 0 & 6.8 \\
\hline 1 & 0.05 & 6.7 \\
\hline 2 & 0.10 & 6.3 \\
\hline 4 & 0.16 & 6.6 \\
\hline 7.5 & 0.29 & 6.2 \\
\hline 22 & 0.57 & 6.3 \\
\hline 24 & 0.58 & 6.4 \\
\hline
\end{tabular}

Table 11. Alteration of an unbuffered aqueous solution in a disposable syringe caused by substances entering the solution from the syringe material and absorbing at $280 \mathrm{~nm}$

\section{Use of large-volume CM bottles}

For intravascular CM investigations, large-volume bottles $(500 \mathrm{ml})$ are sometimes used for reasons of economy, easier handling and better radiation protection of staff. The contrast media are administered with automatic injectors or infusion pumps, which are filled from the $500 \mathrm{ml}$ bottles using appropriate transfer systems. Intentionally unfavorable conditions such as touching the surface of the stopper or the mini-spike with the fingers were created in carefully designed studies but even these conditions caused only minimal contamination of the contrast media. No proliferation of micro-organisms in Ultravist was observed within 24 hours [26, 27]. Likewise, under the conditions of angiography, no relevant microbial contamination had appeared by the end of the angiographic examination when Ultravist was left in open containers [27]. 
Open Access This chapter is licensed under the terms of the Creative Commons Attribution 4.0 International License (http://creativecommons.org/licenses/by/4.0/), which permits use, sharing, adaptation, distribution and reproduction in any medium or format, as long as you give appropriate credit to the original author(s) and the source, provide a link to the Creative Commons license and indicate if changes were made.

The images or other third party material in this chapter are included in the chapter's Creative Commons license, unless indicated otherwise in a credit line to the material. If material is not included in the chapter's Creative Commons license and your intended use is not permitted by statutory regulation or exceeds the permitted use, you will need to obtain permission directly from the copyright holder. 